\title{
Progresso da cercosporiose (Cercospora coffeicola Berkeley \& Cooke) em cafeeiros sob cultivos orgânico e convencional*
}

\author{
Florisvalda da Silva Santos ${ }^{1 * *}$, Paulo Estevão de Souza ${ }^{2}$, Edson Ampélio Pozza², Júlio César Miranda², Sarah Silva \\ Barreto $^{2}$, Vanessa Cristina Theodoro ${ }^{3}$.
}

\begin{abstract}
${ }^{1}$ Universidade do Estado da Bahia, Campus IX, Rodovia 242, km 04, Flamengo, CEP 47800-000, Barreiras, BA, fax: (77) 3611.3950; e-mail: flvsantos@yahoo.com.br. ${ }^{2}$ Departamento de Fitopatologia, Universidade Federal de Lavras, ${ }^{3}$ Departamento de Agricultura, Universidade Federal de Lavras. *Parte da Tese de Doutorado do primeiro autor. Universidade Federal de Lavras (2006). ** Bolsista CAPES.

Autor para correspondência: Florisvalda da S. Santos.
\end{abstract}

Data de chegada:13/12/2006. Aceito para publicação em: 29/10/2007

\section{RESUMO}

Santos, F. da S., Souza, P.E., Pozza, E.A., Miranda, J.C., Barreto, S.S., Theodoro, V.C. Progresso da cercosporiose (Cercospora coffeicola Berkeley \& Cooke) em cafeeiros sob cultivos orgânico e convencional. Summa Phytopathologica, v.34, n.1, p.48-54, 2008

Avaliou-se o progresso da cercosporiose em cafeeiros sob sistemas de produção orgânico e convencional no município de Santo Antônio do Amparo, MG, entre novembro/2003 e novembro/2005. As lavouras, que são vizinhas, encontravam-se sob condições similares de clima, solo e relevo e eram formadas por cafeeiros cv. Acaiá MG-47419, de dez anos. A doença foi mais intensa no sistema de produção convencional, cuja média de dois anos consecutivos de avaliações demonstrou área abaixo da curva de progresso da cercosporiose maior $(3,905)$ do que o orgânico $(2,529)$. Isso ficou demonstrado também pela incidência máxima nas folhas, equivalente a $28 \% \mathrm{em}$ 2004 e $29 \%$ em 2005, enquanto no sistema orgânico foi de $9 \%$ e $12 \%$, respectivamente. Nos frutos, a incidência foi de $18,2 \% \mathrm{em}$ 2004 e $22 \%$ em 2005, enquanto no orgânico foi de $11,5 \%$ e $15 \%$, respectivamente. A maior suscetibilidade dos cafeeiros à cercosporiose no sistema convencional coincidiu com menores teores de cálcio e magnésio foliares nas fases de granação e maturação dos frutos comparados ao orgânico, conseqüência da maior carga pendente que resultou em uma produtividade superior em 26,8 sc/ha ao orgânico em 2004 (alta carga pendente). Em 2005 a produtividade foi estatisticamente semelhante em ambos os sistemas. Houve menor alternância entre a produtividade das duas safras consecutivas no sistema orgânico (34\% menor em 2005) quando comparada à convencional (64\% menor) sugerindo uma tendência de menor efeito da doença sobre a safra seguinte dos cafeeiros no sistema orgânico de produção, comparado ao convencional.

Palavras chave: Epidemiologia, nutrição, produtividade.

\section{ABSTRACT}

Santos, F. da S., Souza, P.E., Pozza, E.A., Miranda, J.C., Barreto, S.S., Theodoro, V.C. Progress of brown eye spot (Cercospora coffeicola Berkeley \& Cooke) in coffee trees in organic and conventional systems. Summa Phytopathologica, v.34, n.1, p.48-54, 2008

The progress of brown eye spot in coffee trees in both organic and conventional crop systems was evaluated in two neighboring fields, in Santo Antônio do Amparo city, MG, between nov./2003 and nov./2005. The fields are under similar weather, soil and relief conditions and made up of ten-year-old coffee trees cv. Acaiá MG474-19. The incidence of brown eye spot was significantly higher in conventional system, whose average from two years demonstrated the area under the disease progress curve (3.905) higher than organic system (2.529). That was also demonstrated by the higher incidence on leaves (maximum 28\% in 2004 and $29 \%$ in 2005) on conventional than on organic system ( $9 \%$ and $12 \%$, respectively). The incidence on fruits was $18.2 \%$ in 2004 and $22 \%$ in 2005 , while on organic system it was $11.5 \%$ and $15 \%$, respectively. This higher susceptibility to disease on coffee trees in conventional system coincided with lower foliar content of calcium and magnesium for the fruit filling and fruit ripening stages compared with to the organic system. That was a consequence of higher production of the conventional system that resulted in yield $47.8 \%$ higher than organic one in 2004 (high number of berries). In 2005, the yield was similar in both crop systems but it was verified that the conventional production in 2005 was $64 \%$ lower than in 2004 whereas in the organic system from the difference in yield was $34 \%$. This suggested for a tendency of lower effect of the disease in the following coffee harvest of the organic system compared to the conventional one.

\section{Additional keywords: Epidemiology, nutrition, yield.}

A cafeicultura orgânica procura conciliar produção e auto sustentabilidade com o caráter sócio-ambiental. Para isso suas práticas de manejo restringem o uso de fungicidas e utilizam matéria orgânica como principal fonte nutricional dos cafeeiros. Tais particularidades tornaram o café produzido nesse sistema um produto atraente para um mercado potencial. Porém, técnicos e cafeicultores reconhecem as doenças como principal ponto de estrangulamento na produtividade do café orgânico e, dentre estas doenças destaca-se a cercosporiose (Cercospora coffeicola Berkeley \& Cooke), causando lesões em folhas e frutos, ocasionando danos na produção e no rendimento.

Os relatos sobre o progresso das doenças do cafeeiro em sistema de produção orgânico e as diferenças decorrentes desse manejo 
nutricional diferenciado ainda são escassos. Na Costa Rica, Samayoa \& Sanchez (26) relataram maior incidência da cercosporiose em lavoura convencional comparada à orgânica. Na Malásia, Phiri et al. (23) registraram incidência de $40 \%$ de cercosporiose em lavouras de café orgânico. No Brasil, Martins et al. (21) registraram incidência de cercosporiose acima de 59\% em cafeeiros orgânicos, em Minas Gerais, mas não mencionaram o efeito da doença na produtividade das lavouras avaliadas. Também em Minas Gerais, Teixeira et al. (28) observaram menor intensidade da cercosporiose em lavoura orgânica comparada à convencional, com incidência máxima de 3 e 15\%, respectivamente.

O progresso dessa doença é favorecido por vários fatores relacionados ao patógeno, hospedeiro e ambiente. Período de molhamento foliar de 6 a 12 horas resulta em máxima severidade da cercosporiose e o período de incubação médio de C. coffeicola é de 16 dias $(09,10)$. De modo geral, os conídios podem sobreviver por mais de sete semanas em folhas destacadas e permanecerem viáveis por quase nove meses na superfície foliar aguardando condições favoráveis para germinarem, como temperatura ótima em torno de $24{ }^{\circ} \mathrm{C}(08)$. O estresse hídrico e o desequilíbrio nutricional propiciam maior severidade (11) e, da mesma forma, o desequilíbrio entre o cálcio e o potássio tende a aumentar a suscetibilidade do cafeeiro à cercosporiose $(12,24)$. Esse desequilíbrio pode ser causado por grande produção, ausência de chuvas ou excesso de adubação em cobertura sem a devida calagem (05). Esse conhecimento foi gerado a partir de estudos da doença em cafeeiros conduzidos em sistema de produção denominado convencional, no qual a nutrição das plantas se baseia no uso de adubos minerais prontamente solúveis. Até o momento, pouco se estudou sobre a intensidade da cercosporiose em sistema de produção orgânico. Nesse sistema a liberação de nutrientes das fontes de adubação orgânicas para a planta é feita de forma mais lenta que na mineral (16), podendo existir comportamento diferenciado das doenças em função dessa característica. Estudos comparativos de epidemias nos cultivos convencional e orgânico podem possibilitar identificar diferenças relevantes em função dos níveis nutricionais das plantas e da produtividade peculiares aos dois sistemas. Isso é pré-requisito para estabelecer qualquer manejo fitossanitário da forma mais racional possível $(01,04,29)$.

Assim, o presente estudo avaliou comparativamente a cercosporiose em cafeeiros sob sistema de cultivo orgânico e convencional, relacionando o progresso da doença às características nutricionais, ao enfolhamento e à produtividade.

\section{MATERIAL E MÉTODOS}

O experimento foi conduzido em duas lavouras vizinhas, sendo uma cultivada sob sistema orgânico e outra convencional, sem irrigação, localizadas no município de Santo Antônio do Amparo, MG, durante os anos agrícolas 2003/2004 e 2004/2005. A área experimental está localizada a $1.021 \mathrm{~m}$ de altitude nas coordenadas geográficas $20^{\circ} 53^{\prime} 026^{\prime \prime}$ de latitude sul e $44^{\circ} 57^{\prime} 026^{\prime \prime}$ de longitude oeste. O sistema de produção de café da Fazenda Cachoeira caracteriza-se, desde 1995, pelo manejo da lavoura de acordo com as normas técnicas de produção orgânica do Instituto Biodinâmico (IBD). O sistema de produção de café convencional localiza-se na Fazenda Taquaril. Ambas as lavouras possuíam cafeeiros cv. Acaiá MG/474-19 com oito anos, no início do experimento, com espaçamento de plantio 2,0 x 1,0 m nos dois sistemas. Durante a condução do experimento, as lavouras receberam os mesmos tratos culturais pertinentes aos seus sistemas de manejo com poucas variações (Tabela 1). A quantidade de adubo aplicada foi recomendada com base na análise do solo após a colheita e critérios de interpretação dos níveis de fertilidade propostos pela $5^{\text {a }}$ Aproximação das Recomendações para Uso de Corretivos e Fertilizantes em Minas Gerais (13).

Em cada lavoura delimitaram-se quatro parcelas com 77 plantas, e em cada parcela foram selecionados dez cafeeiros, cujo enfolhamento e cargas pendentes foram os mais uniformes possíveis, para constituírem a unidade experimental.

A incidência e a severidade da cercosporiose (22) foram avaliadas quinzenalmente, entre novembro/2003 e novembro/2005. Avaliaramse 12 folhas por planta, do terceiro ao quarto pares, em ramos plagiotrópicos do terço médio, escolhidos aleatoriamente, em amostragem não destrutiva. Amostras de 400 frutos foram coletadas, separadamente, em três alturas da planta correspondendo aos terços inferior, médio e superior, quando esses se encontravam no estádio próximo à maturidade fisiológica, correspondendo ao fruto "cereja". No caso de dúvida em relação às características das lesões observadas, acondicionaram-se os frutos em câmara úmida por 24 horas para a certificação da diagnose. Quanto à severidade adotouse uma escala de notas, representando a área lesionada do fruto (03): 0 (fruto sem sintoma), 1 ( $1 \%$ a $25 \%$ de área lesionada), 2 $(26 \%$ a $50 \%), 3(>50 \%)$.

Os teores nutricionais dos cafeeiros foram avaliados em três épocas durante o desenvolvimento dos frutos adaptando-se

Tabela 1. Manejo de adubação e pulverizações dos cafeeiros nos sistemas de produção orgânico (ORG) e convencional (CON), em dois ciclos produtivos nos anos agrícolas 2003/2004 e 2004/2005.

\begin{tabular}{|c|c|c|c|c|}
\hline \multirow[t]{2}{*}{ Sistemas } & \multicolumn{2}{|c|}{ Fontes nutricionais } & \multicolumn{2}{|c|}{ Pulverizações } \\
\hline & Ano 2003/2004 & Ano 2004/2005 & Ano $2003 / 2004$ & Ano $2004 / 2005$ \\
\hline ORG & $\begin{array}{l}\text { Composto orgânico }+ \text { torta de } \\
\text { mamona }+ \text { chorume suíno }+ \\
\text { Crotalaria juncea }\end{array}$ & $\begin{array}{l}\text { Composto orgânico }+ \text { torta de } \\
\text { mamona }+ \text { farinha de ossos e } \\
\text { carne }+ \text { C. juncea }\end{array}$ & $\begin{array}{l}\text { Viça-café plus }{ }^{\circledR}(3 \mathrm{~kg} / \mathrm{ha}) \text { em } \\
\text { cinco aplicações de nov. a mar. }\end{array}$ & $\begin{array}{l}\text { Viça-café plus }{ }^{\circledR}(3 \mathrm{~kg} / \mathrm{ha}) \\
\text { em cinco aplicações de } \\
\text { nov. a mar. }\end{array}$ \\
\hline $\mathrm{CON}$ & $\begin{array}{l}\text { Formulado comercial } 20-0-20+ \\
\text { superfosfato simples;calcário } \\
\text { calcítico: } 2 \mathrm{t} / \mathrm{ha} \text {; calda para } \\
\text { fornecimento de boro, zinco, } \\
\text { cobre, cloro e manganês, em três } \\
\text { aplicações, entre dez. e março. }\end{array}$ & $\begin{array}{l}\text { Formulado comercial } 20-0-20+ \\
\text { SH-550 com } 24 \% \text { Fósforo; } \\
\text { calcário calcítico: } 2 \text { t/ha; calda } \\
\text { para fornecimento de boro, zinco, } \\
\text { cobre, cloro e manganês, em três } \\
\text { aplicações, entre dez. e março. }\end{array}$ & $\begin{array}{l}\text { Epoxiconazole + Pyraclostrobin } \\
\text { (1,5 L p.c./ha), em dez. e fev.; } \\
\text { Tebuconazole( } 0,6 \text { L p.c./ha), em } \\
\text { junho (Controle de mancha de } \\
\text { Phoma). }\end{array}$ & $\begin{array}{l}\text { Epoxiconazole } \\
\text { Pyraclostrobin (1,5 L } \\
\text { p.c./ha), em dez. e fev.; } \\
\text { Tebuconazole ( } 0,6 \text { L p.c./ } \\
\text { ha), em nov. }\end{array}$ \\
\hline
\end{tabular}


Tabela 2. Área abaixo da curva de progresso da incidência (AACPI) da cercosporiose em folhas, percentual de incidência da doença em frutos e produtividade de cafeeiros conduzidos sob sistemas orgânico (ORG) e convencional (CON), nas safras 2004 e 2005 (médias de quatro repetições).

\begin{tabular}{|c|c|c|c|c|c|c|c|}
\hline \multirow[t]{2}{*}{ Sistema } & \multicolumn{2}{|c|}{ AACPI } & \multicolumn{2}{|c|}{ Incidência (\%) } & \multicolumn{3}{|c|}{ Produtividade (sc/ha)* } \\
\hline & 2004 & 2005 & 2004 & 2005 & 2004 & 2005 & Média \\
\hline ORG & $2.650 \mathrm{~A}$ & $2.408 \mathrm{~A}$ & $11,5 \mathrm{~A}$ & $15,0 \mathrm{~A}$ & $55,0 \mathrm{Aa}$ & $36,6 \mathrm{Aa}$ & 45,8 \\
\hline
\end{tabular}

* As médias seguidas pelas mesmas letras maiúsculas na coluna e minúsculas na linha não diferem estatisticamente, pelo Teste Tukey, a 5\%.

metodologia de Chaves \& Sarruge (06): 1.- Estádio inicial de desenvolvimento (fase de chumbinho), 2. - Estádio "verde" (fase de expansão ou granação dos frutos) e 3. - Próximos ao ponto de colheita (fase de maturação). Amostras de 100 folhas, coletadas no terceiro par de folhas em ramos do terço médio das plantas, foram encaminhadas para análises dos teores de nitrogênio $(\mathrm{N})$, fósforo $(\mathrm{P})$, potássio $(\mathrm{K})$, cálcio $(\mathrm{Ca})$, magnésio $(\mathrm{Mg})$ e enxofre $(\mathrm{S})$ na matéria seca (17). Os teores de nutrientes e suas alterações nas concentrações nas folhas foram analisados e comparados com os níveis críticos estabelecidos para a cafeicultura.

O enfolhamento foi estimado de duas maneiras. Avaliou-se, quinzenalmente, a ausência de folhas no terceiro e quarto pares de folhas de ramos plagiotrópicos do terço médio dos cafeeiros escolhidos para avaliar as doenças, estimando-se o percentual de desfolha. Avaliou-se, mensalmente, o índice de área foliar (IAF) dos cafeeiros por meio do analisador de dossel das plantas (Lai2000 - Plant Canopy Analyser), fazendo-se leituras em quatro diferentes pontos da unidade experimental. A produção correspondente às safras 2003/2004 e 2004/2005 foi determinada pelo peso dos frutos colhidos na planta e estimou-se a produtividade em sacas por hectare, considerando rendimento médio de $20 \%$.

Instalaram-se uma estação microclimatológica (Campbel Scientific ${ }^{\circledR}$ ) em cada uma das duas propriedades para monitorar as variáveis temperatura e umidade relativa do ar, molhamento foliar e precipitação pluviométrica. Não houve diferenças distintas nos dados coletados nas duas estações devido à proximidade entre as áreas experimentais, de modo que se considerou a média das duas estações. Os dados foram relacionados ao progresso da doença

Os índices médios de incidência e de severidade da cercosporiose foram transformados em área abaixo da curva de progresso da incidência (AACPI) e da severidade (AACPS), conforme Shaner \& Finney (27) e os índices médios da área foliar e da desfolha foram transformados em área abaixo da curva de progresso da desfolha (IAACPDesf) e do índice da área foliar (AACPIAF). Com os dados de percentagem da incidência da doença foi calculada também a taxa de progresso. Os valores de AACPI, AACPS, AACPDesf, AACPIAF, os percentuais de incidência e de severidade da doença nos frutos e a produtividade foram submetidos à análise de variância pelo teste $\mathrm{F}$ e ao teste de média. Os sistemas de produção foram também comparados quanto ao estado nutricional dos cafeeiros. Os dados foram analisados pelo programa estatístico SAS (Statistical Analysis System ver. 8.0; SAS Institute Inc. Cary, NC).

\section{RESULTADOS E DISCUSSÃO}

Constatou-se o efeito dos sistemas de produção na incidência da cercosporiose com maior área abaixo da curva de progresso da doença
( $\mathrm{P}=0,0004)$ em cafeeiros conduzidos em sistema convencional (3.905) do que em sistema orgânico (2.529), conforme média de dois anos consecutivos de avaliações. Isso está de acordo com relatos de Samayoa \& Sanchez (26) sobre a maior intensidade da doença em lavoura convencional da Costa Rica, quando comparada à orgânica. Resultados similares foram observados por Teixeira et al. (28) com incidências máximas equivalentes a $15 \%$ e 3\% em lavoura convencional e orgânica, respectivamente. Da mesma forma que nas folhas, a incidência da doença nos frutos foi menor nos cafeeiros orgânicos, cujo percentual de frutos lesionados foi de $11,5 \%$ em 2004 e $15 \%$ em 2005, enquanto no sistema convencional foi de $18,2 \%$ e $22 \%$, respectivamente (Tabela 2). A severidade verificada nos frutos localizados no terço superior desses cafeeiros foi mais elevada $(\mathrm{P}=0,0062)$ que nos terços médio e inferior $(42,5 \%, 25,7 \%$ e $18,2 \%$, respectivamente, de área lesionada no fruto). A influência dessa posição do fruto é justificada por ser a porção da planta mais exposta ao sol, devido à baixa densidade foliar encontrada no topo do cafeeiro. A relação entre C. coffeicola e a intensidade luminosa foi relatada por Echandi (08) e, de acordo com Daub et al. (07), espécies do gênero Cercospora produzem a toxina cercosporina, a qual é ativada na presença de alta intensidade luminosa, causando necrose.

As curvas de progresso da cercosporiose tiveram configurações distintas nos anos agrícolas 2003/2004 e 2004/2005 (Figura 1). Analisando a curva de progresso da doença em cada ano, separadamente, verifica-se que a variável área abaixo da curva de progresso da incidência não diferiu estatisticamente nos dois sistemas no primeiro ano (Tabela 2), mas enquanto a incidência máxima verificada em julho nos cafeeiros orgânicos era de $9 \%$ em 2004 e 12\% em 2005, no sistema convencional era de $28 \%$ e $29 \%$, respectivamente. Esses picos de incidência foram resultados da elevação no progresso da doença durante o período de frutificação, quando os cafeeiros ficam mais propensos ao desequilíbrio nutricional, devido a um maior dreno de nutrientes das folhas para o enchimento dos grãos, tornando as plantas mais suscetíveis à cercosporiose, como observado por Fernández-Borrero et al. (11). Considerando que, no presente estudo, ambas as lavouras encontravamse sob mesmo tipo de solo, disponibilidade de água, cultivar, idade da cultura e clima, ou seja, fatores normalmente relacionados ao progresso da epidemia, a principal variável diferenciada nesses patossistemas foi o sistema de manejo referente à nutrição das plantas.

Com relação ao estado nutricional dos cafeeiros, ambos os sistemas de produção propiciaram teores de nitrogênio, potássio e enxofre foliar similares, na fase chumbinho (Tabela 3). Esses nutrientes estiveram acima da faixa crítica considerando-se os critérios de Martinez et al. (20) para lavouras com produção acima de 30 sacas/ha na região Sul de Minas, e as faixas sugeridas por Guimarães et al. (13) e Malavolta et al. (17) para a cafeicultura. Os sistemas de produção afetaram os teores de cálcio $(\mathrm{P}=0,0112)$ e de magnésio $(\mathrm{P}=0,0120)$ foliares como se observou no segundo ano de estudo. $\mathrm{O}$ teor de cálcio encontrado no sistema convencional $\left(7,92 \mathrm{~g} . \mathrm{kg}^{-1}\right)$ foi inferior ao orgânico $\left(10,57 \mathrm{~g} . \mathrm{kg}^{-}\right.$ $\left.{ }^{1}\right)$ e esteve abaixo da faixa adequada entre 10,0 e 13,0 g. $\mathrm{kg}^{-1}$ sugerida 


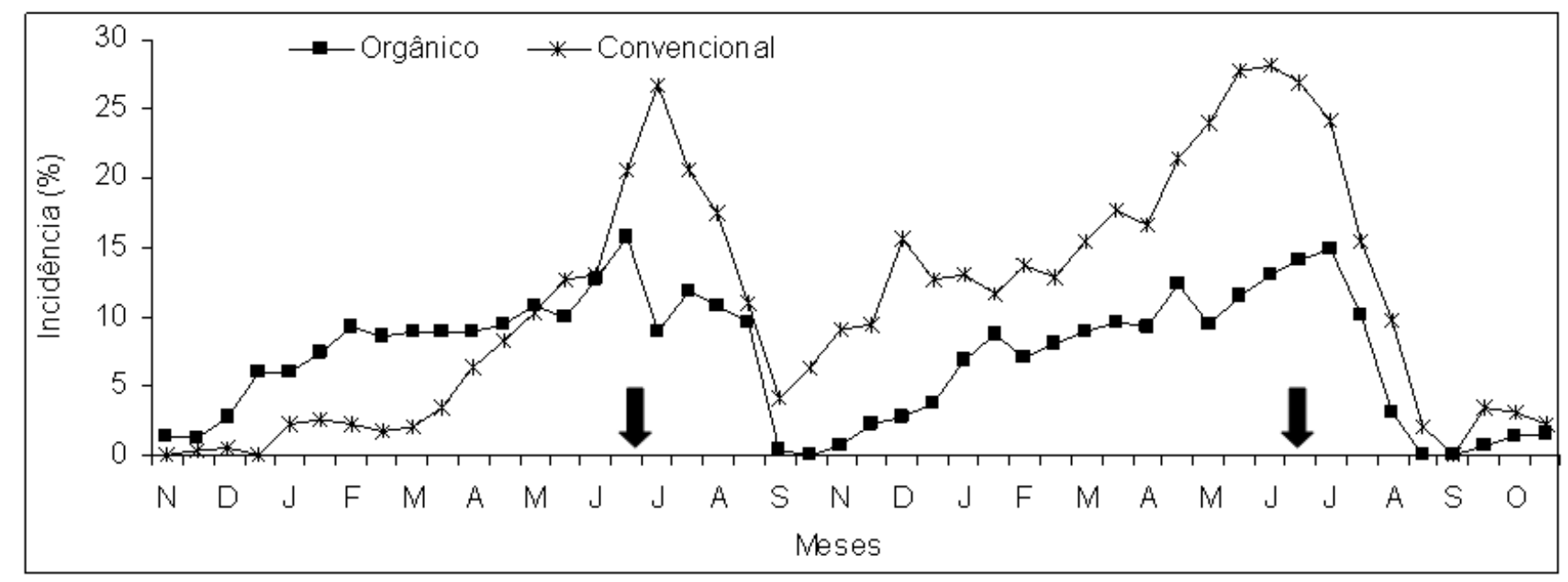

Figura 1. Curvas de progresso da cercosporiose em cafeeiros nos sistemas de produção orgânico e convencional, entre novembro/2003 e novembro/2005. As setas indicam a época da colheita (médias de quatro repetições).

por Guimarães et al. (13) ou 8,4 e 14,0 g. $\mathrm{kg}^{-1}$ sugerida por Martinez et al. (20), para lavouras de média a alta produção. Teores de magnésio foliar menores e abaixo dos teores adequados (3,1 a 4,5 g. $\mathrm{kg}^{-1}$ ) sugeridos por Guimarães et al. (13) foram encontrados também nos cafeeiros do sistema convencional $\left(2,58{\mathrm{~g} . \mathrm{kg}^{-1}}^{-1}\right)$ comparados ao orgânico $\left(3,3\right.$ g. $\left.\mathrm{kg}^{-1}\right)$.

Vale ressaltar, entretanto, que o estado nutricional dos cafeeiros em ambos os sistemas de produção não explicaria as diferenças no progresso da doença ao se considerar, isoladamente, as amostragens feitas na fase chumbinho. Como visto nesta fase do ciclo produtivo do cafeeiro, os teores de nutrientes não diferenciaram entre os sistemas, exceto o fósforo foliar e, ainda assim, este se encontrava dentro da faixa adequada à cafeicultura. Teores de nutrientes estabelecidos como faixa crítica (20) ou faixa adequada $(13,17)$ são determinados na fase chumbinho, possibilitando avaliar o estado nutricional dos cafeeiros antes de ocorrer o enchimento de grãos e comparados aos padrões obtidos de plantas altamente produtivas da mesma espécie e variedade, cujos níveis críticos nutricionais já foram previamente estabelecidos. Essa avaliação define, conforme Malavolta \& Cruz (18), a faixa de concentração do nutriente na folha abaixo da qual a produção é limitada e acima da qual a adubação não é econômica. De acordo com as análises foliares realizadas durante as fases subseqüentes da frutificação foram verificadas alterações nutricionais que podem estar relacionadas ao elevado progresso da doença nestas fases do ciclo produtivo do cafeeiro orgânico. Da fase chumbinho para a fase de maturação dos frutos houve redução na concentração foliar dos nutrientes, conforme verificado no sistema orgânico em 2004 e 2005 para nitrogênio (27 e $12 \%$ ), fósforo ( 10 e $25 \%$ ), potássio ( 26 e $20 \%$ ), cálcio (12 e $6 \%$ ) e magnésio (22 e 5\%). Essa alteração nas concentrações deve-se ao dreno de nutrientes desviados das folhas para os frutos durante a frutificação do cafeeiro (06). Da fase de granação dos frutos para a de maturação, quando o progresso da cercosporiose se elevou consideravelmente, a redução nas concentrações nutricionais de cálcio e de magnésio foram ressaltadas (Tabela 4) chegando a $45 \%$ e $29 \%$, respectivamente, no orgânico e $52 \%$ e $37 \%$, respectivamente, no convencional. Esses resultados corroboram as observações feitas por Chaves \& Sarruge (06) sobre reduções de cálcio e magnésio nos tecidos foliares do cafeeiro ao final da granação. Em ambas as fases os teores de cálcio e de magnésio foliares foram significativamente menores nos cafeeiros no sistema convencional, comparado ao orgânico. O comportamento dessas variáveis coincidiu com o elevado progresso da doença observado no sistema convencional e tem relação com a variável produção avaliada nos dois ciclos produtivo dessas lavouras.

A produção dos cafeeiros foi maior no sistema convencional, considerando a média de duas safras (Tabela 2) e chegou a obter uma produtividade de $26,8 \mathrm{sc} / \mathrm{ha}$ a mais $(\mathrm{P}=0,028)$ que o orgânico em 2004 , ano de alta carga pendente. A menor produtividade dos cafeeiros orgânicos deve ter contribuído para uma menor intensidade da

Tabela 3. Teores de N, P, K, Ca, Mg e S foliares em cafeeiros conduzidos sob sistemas orgânico (ORG) e convencional (CON), na fase equivalente a "Chumbinho" nos anos agrícolas 2003/2004 e 2004/2005 (médias de quatro repetições).

\begin{tabular}{|c|c|c|c|c|}
\hline \multirow[t]{2}{*}{ Nutrientes (g.kg $\left.{ }^{-1} \mathrm{MS}\right)$} & \multicolumn{2}{|c|}{$2003 / 2004$} & \multicolumn{2}{|c|}{$2004 / 2005$} \\
\hline & ORG & CON & ORG & CON \\
\hline $\mathrm{N}$ & $33,5 \mathrm{a}^{*}$ & $35,8 \mathrm{a}$ & $34,6 \mathrm{a}$ & $33,6 \mathrm{a}$ \\
\hline $\mathrm{P}$ & $2,2 \mathrm{~b}$ & $1,2 \mathrm{a}$ & $2,5 \mathrm{~b}$ & $1,2 \mathrm{a}$ \\
\hline K & $25,5 \mathrm{a}$ & 26,9 a & 26,3 a & 28,6 a \\
\hline $\mathrm{Ca}$ & 8,6 a & 9,9 a & $10,6 \mathrm{~b}$ & 7,9 a \\
\hline $\mathrm{Mg}$ & $3,1 \mathrm{a}$ & $2,8 \mathrm{a}$ & $3,5 \mathrm{~b}$ & $2,4 \mathrm{a}$ \\
\hline $\mathrm{S}$ & $2,2 \mathrm{a}$ & $2,2 \mathrm{a}$ & $2,4 \mathrm{a}$ & $2,2 \mathrm{a}$ \\
\hline
\end{tabular}

* As médias seguidas pelas mesmas letras na linha não diferem estatisticamente, pelo Teste Tukey, a 5\%. 


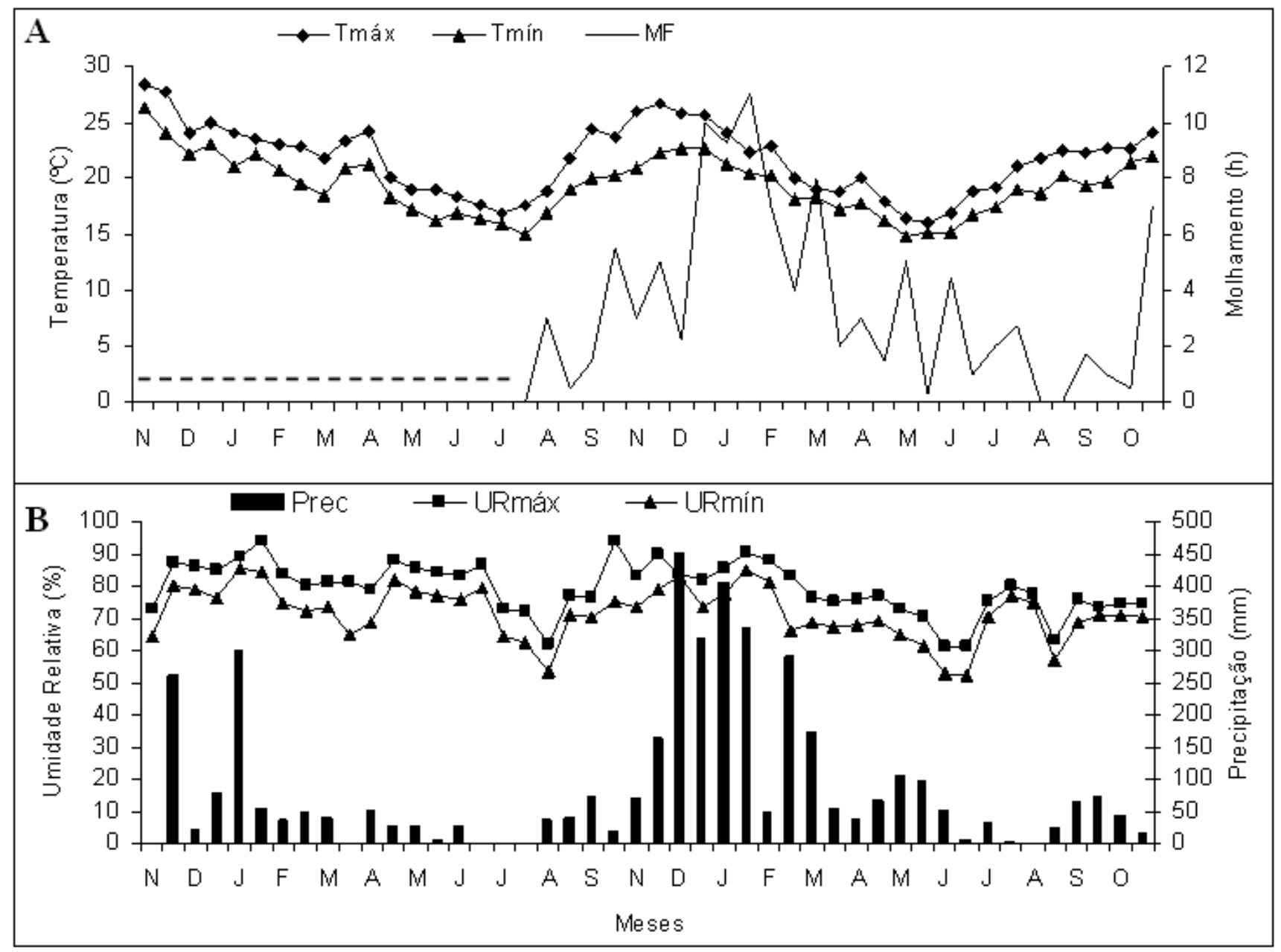

Figura 2. Variáveis ambientais no período de nov./2003 a nov./2005. A: Temperaturas máxima (Tmáx) e mínima (Tmín) e Horas de duração de molhamento foliar (MF). B: Precipitação pluviométrica (Prec.) e Umidade relativa do ar máxima (URmáx) e mínima (URmín). Linha tracejada indica ausência de dados de MF.

Tabela 4. Teores de cálcio e de magnésio na matéria seca de folhas de cafeeiros nos sistemas de produção orgânico e convencional, em diferentes fases de desenvolvimento dos frutos: chumbinho (Ch.), granação (Gr.) e maturação (Mat.), no ano agrícola 2003/2004 (médias de quatro repetições).

\begin{tabular}{llccccc}
\hline Nutriente & Sistemas de produção & \multicolumn{3}{c}{ Fases de desenvolvimento do fruto } \\
& & Ch.* & Gr.* & Mat.* \\
\hline & ORG & $8,6 \mathrm{Aa}$ & 13,7 & $\mathrm{Bb}$ & $7,5 \mathrm{Ba}$ \\
$\mathrm{Ca}\left(\mathrm{g} \mathrm{kg}^{-1}\right)$ & $\mathrm{CON}$ & $9,9 \mathrm{Ab}$ & $9,5 \mathrm{Ab}$ & 4,7 & $\mathrm{Aa}$ \\
$\mathrm{Mg}\left(\mathrm{g} \cdot \mathrm{kg}^{-1}\right)$ & ORG & $3,1 \mathrm{Aab}$ & $3,4 \mathrm{Bb}$ & $2,4 \mathrm{Ba}$ \\
& & $\mathrm{CON}$ & $2,8 \mathrm{Ab}$ & $2,5 \mathrm{Ab}$ & $1,6 \mathrm{Aa}$ \\
\hline
\end{tabular}

* As médias seguidas pelas mesmas letras maiúsculas na coluna e minúsculas na linha não diferem estatisticamente, pelo Teste Tukey, a 5\%.

cercosporiose, pois quando a produtividade é menor reduz-se o dreno para a frutificação ficando uma maior concentração de nutrientes nas folhas amostradas (16). Com menor carga pendente, possivelmente houve uma maior resistência dos cafeeiros orgânicos à infecção por $C$. coffeicola. Ao contrário, o desequilíbrio observado nos teores de cálcio, magnésio e fósforo foliares nos cafeeiros do sistema convencional pode ser relacionado ao maior dreno conseqüente de sua produção
48,7\% superior. Essa extração de nutrientes mais elevada das folhas para a alta carga pendente propiciou maior suscetibilidade dos cafeeiros à infecção pelo patógeno, resultando em maior progresso da cercosporiose.

A relação entre a nutrição de cafeeiros e a cercosporiose foi enfatizada por Garcia Júnior et al. (12) ao demonstrarem a importância do suprimento de cálcio na intensidade da doença a qual teve a incidência reduzida com o aumento de doses do nutriente em mudas de cafeeiro. $\mathrm{O}$ cálcio é essencial na lamela média na forma de pectato de cálcio, fortalecendo a parede celular, que funciona como barreira física à penetração do patógeno (19). O magnésio, como constituinte da clorofila, é importante na fotossíntese, sendo associado ao crescimento das plantas, à ativação de enzimas e à fosforilação oxidativa em células fisiologicamente jovens $(14,19)$. O fósforo foliar foi o único macronutriente que demonstrou diferenças significativas entre os sistemas de produção, nos dois anos de estudo $(\mathrm{P}=0,0001)$, com teores mais elevados no sistema orgânico. Existem referências às interações do fósforo com a intensidade das doenças em plantas (30), mas a relação desse nutriente com a cercosporiose tem sido contraditória $(09,24)$ e apesar de mais elevado no sistema orgânico, em ambos os sistemas, não houve deficiência ou excesso de fósforo considerando a faixa crítica para o cafeeiro (20). Fontes 


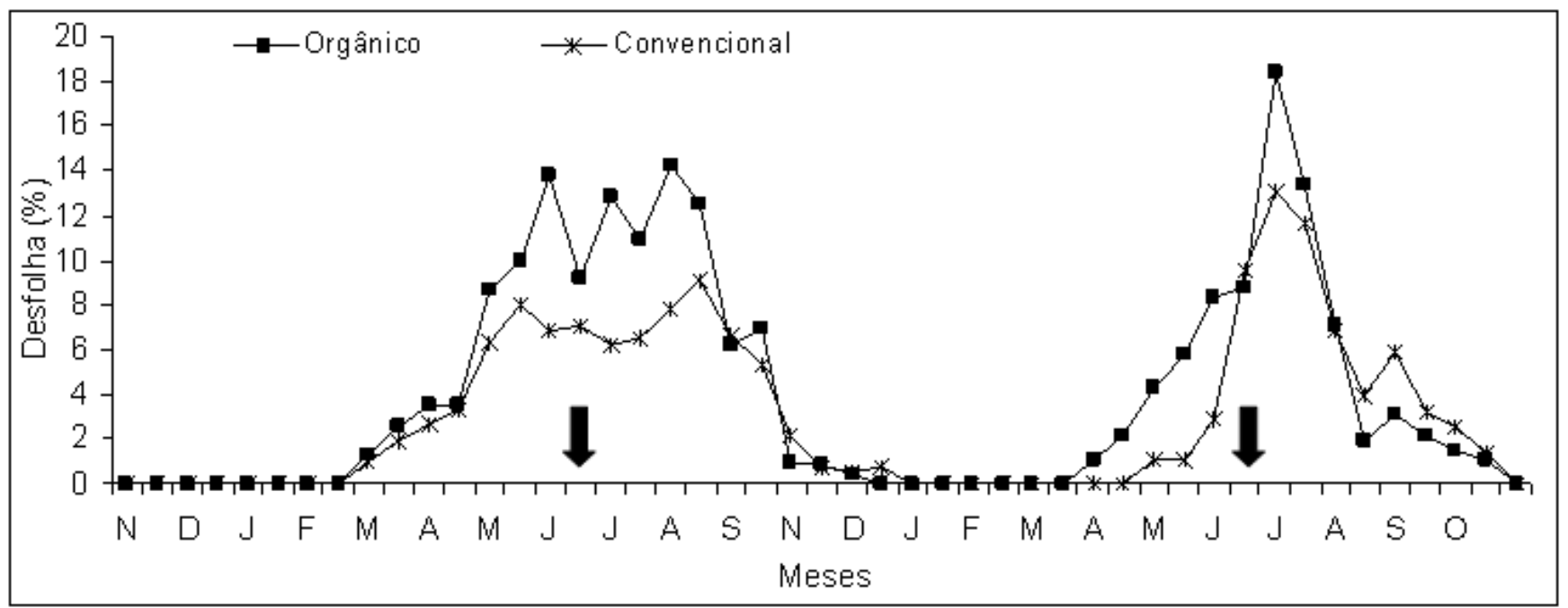

Figura 3. Percentuais de desfolha em cafeeiros nos sistemas de produção orgânico e convencional, entre novembro/2003 e novembro/2005. As setas indicam a época de colheita (médias de quatro repetições).

orgânicas, de acordo com Kiehl (16), possibilitam aumentar a disponibilidade dos nutrientes e fornecê-los de forma mais lenta às plantas, e contribuem para reduzir a fixação do fósforo no solo.

Houve um progresso diferenciado da cercosporiose no segundo ciclo produtivo dos cafeeiros com relação ao início da infecção. No início das avaliações, em novembro de 2003, não foram observadas diferenças quanto à incidência, registrando-se percentuais inferiores a $5 \%$ nos dois sistemas de produção. Entretanto, em novembro do ano seguinte, foram registrados percentuais ao redor de $10 \%$ de incidência em cafeeiros no sistema convencional. No orgânico esses valores foram novamente inferiores a 5\% (Figura 1). Essa antecipação na elevação da doença pode ter sido decorrente do inóculo remanescente da alta incidência em julho/2004 no sistema convencional favorecido por temperatura em torno de $24{ }^{\circ} \mathrm{C}$, registrada em setembro e outubro de 2004 (Figura 2A), permitindo visualizar sintomas da cercosporiose em elevada incidência no mês seguinte. Com a formação de novas brotações ao final de 2004 e a elevação no molhamento foliar (Figura 2A) em torno de 2 horas em média, tempo suficiente para germinação e penetração dos conídios $(08,10), C$. coffeicola encontrou condições favoráveis para a infecção. Presume-se que o maior volume e a melhor distribuição pluviométrica ocorridos na região em 2005 (Figura 2B) comparados ao ano anterior favoreceram o patógeno, propiciando umidade para a germinação dos conídios e contribuindo para a dispersão do inóculo na lavoura. A incidência da cercosporiose no sistema convencional permaneceu superior à observada no orgânico até agosto de 2005,

Quanto ao enfolhamento dos cafeeiros, observou-se um percentual de desfolha nos ramos significativamente diferente nos dois sistemas apenas nos meses de maio a agosto (Figura 3). Nesse período, que abrange os meses anteriores à colheita até o final da mesma, houve maior área abaixo da curva de progresso da desfolha nos cafeeiros orgânicos $(\mathrm{P}=0,0400)$. A perda de folhas mais acentuada foi também confirmada pela variável área abaixo da curva de progresso do índice de área foliar, cujo valor foi menor no orgânico (1.595) comparado ao convencional (1.798). É interessante salientar que nos cafeeiros orgânicos a incidência da cercosporiose ocorreu simultaneamente à incidência da ferrugem (Hemileia vastatrix), contribuindo para aumentar a desfolha, enquanto no cultivo convencional a ferrugem foi praticamente mantida sob controle à base de fungicidas, resultando em melhor enfolhamento destes cafeeiros. Ao final de agosto, quando se registrou a menor quantidade de folhas novas, mais suscetíveis ao fungo, verificou-se também redução drástica na intensidade da cercosporiose nos dois sistemas. Ressalta-se a capacidade dos cafeeiros orgânicos recuperarem a folhagem, igualando-se em área foliar aos cafeeiros no sistema convencional. Em junho, antes da colheita o IAF dos cafeeiros foi estimado em 4,6 no orgânico e 7,0 no convencional, mas logo com as primeiras chuvas, após o lançamento de folhas novas, o IAF estimado foi equivalente a 4,0 e 4,4, respectivamente.

É interessante salientar que a redução na produção ocorrida de uma safra para a outra no orgânico foi de $33,5 \%$ enquanto no sistema convencional foi de $64 \%$. A alternância da produção mais evidente neste sistema sugere um esgotamento acentuado dos cafeeiros, o qual, em longo prazo, pode significar menor tempo útil da lavoura (26). Além disso, considerando o impacto simultâneo da cercosporiose e da ferrugem (dados não apresentados) sobre a perda de folhas verificada no sistema orgânico, infere-se sobre uma maior capacidade destes cafeeiros recuperarem o enfolhamento e ainda reduzir o efeito de bienalidade da produção.

Além de uma produção menor ter propiciado uma condição nutricional melhor aos cafeeiros orgânicos, há de se considerar também uma maior eficiência das fontes nutricionais exclusivamente orgânicas em fornecer cálcio, magnésio e fósforo aos cafeeiros. Dentre os benefícios da adubação orgânica, estão o aumento na disponibilidade dos nutrientes e seu fornecimento de forma mais lenta às plantas e, ainda, contribuição para diminuir a fixação de fósforo (15). Além disso, a adubação verde com Crotalaria juncea, utilizada no sistema orgânico, aumenta a disponibilidade de nutrientes, bem como a infiltração e a capacidade de retenção de água no solo, importantes na absorção dos nutrientes (25). E, realmente, o estado nutricional do sistema orgânico no presente estudo pode ser considerado mais equilibrado quando se verifica maiores teores de nutrientes nas folhas desses cafeeiros em época de intensificação da cercosporiose, comparado ao sistema convencional. Mas, apesar dos benefícios das fontes nutricionais orgânicas os desequilíbrios temporários verificados podem resultar em maior progresso de doenças. Assim, investigar um manejo de adubação orgânica que possa minimizar as alterações nos teores de cálcio e 
magnésio nas fases de granação e de maturação verificadas no presente trabalho, pode ser uma importante contribuição para reduzir o impacto da doença sobre a cafeicultura, principalmente, numa condição de manejo cujo uso de fungicidas é restringido.

\section{AGRADECIMENTOS}

Os autores agradecem À Fundação de Amparo à Pesquisa de Minas Gerais (FAPEMIG) pelo auxílio financeiro, aos proprietários da Fazenda Cachoeira e Fazenda Taquaril pelo apoio na instalação e condução dos experimentos e ao Sr. Ivan Caixeta, representante da Associação de Cafeicultura Orgânica do Brasil (ACOB), pelo apoio logístico sobre o sistema e as normas de produção de café orgânico.

\section{REFERÊNCIAS BIBLIOGRÁFICAS}

1. Bergamin Filho, A.; Amorim, L. Doenças de plantas tropicais: epidemiologia e controle econômico. São Paulo: Agronômica Ceres, 1996. 299p.

2. Bruggen, A.H.C. Plant disease severity in high-input compared to reduce-input and organic farming systems. Plant Disease, St Paul, v.79, n.10, p.976-984, 1995.

3. Boldini, J.M. Epidemiologia da ferrugem e da cercosporiose do cafeeiro (Coffea arabica L.) irrigado e fertirrigado por gotejamento. 2001. 34 f. Dissertação (Mestrado em Fitopatologia) - Universidade Federal de Lavras, Lavras.

4. Campbell, C.L.; Madden, L.V. Introduction to plant disease epidemiology. New York: John Wiley, 1990. 532p.

5. Chalfoun, S.M. Doenças do cafeeiro: importância, identificação e métodos de controle. Lavras: UFLA/FAEPE. 1998. 93p

6. Chaves, J.C.D.; Sarruge, J.R. Alterações nas concentrações de macronutrientes nos frutos e folhas do cafeeiro durante um ciclo produtivo. Pesquisa Agropecuária Brasileira, Brasília, v.19, n.1, p.427-432, 1984.

7. Daub, M.E.; Herrero, S.; Chung, K. Photoactivated perylenequinone toxins in fungal pathogenesis of plants. FEMS Microbiology Letters, London, v.252, n.1, p.197-206, 2005.

8. Echandi, E. La chasparria de los cafetos causada por el hongo Cercospora coffeicola, Berk ; Cooke. Turrialba, San Jose, v.9 n.2, p.54-67, 1959 .

9. Fernandes, C.D. Efeito de fatores do ambiente e da concentração de inóculo sobre a cercosporiose do cafeeiro. 1988 37 f. Dissertação (Mestrado em Fitopatologia) - Universidade Federal de Viçosa, Viçosa.

10. Fernandes, C.D.; Peloso, M.C.; Maffia, L.A.; Vale, F.X.R.; Zambolim, L. Influência da concentração de inóculo de Cercospora coffeicola e do período de molhamento foliar na intensidade da cercosporiose do cafeeiro. Fitopatologia Brasileira, Brasília, v.16, n.1, p.39-43, 1991.

11. Fernández-Borrero, O.; Mestre, A.M.; Duque, S.L. Efecto de la fertilización en la incidencia de la mancha de hierro (Cercospora coffeicola) en frutos de cafe. Cenicafe, Chinchiná, v.17, n.1, p.5-16, 1966 .

12. Garcia Júnior, D.; Pozza, E.A.; Pozza, A.A.A.; Souza, P.E.; Caarvalho, J.G.; Balieiro, A.C. Incidência e severidade da cercosporiose do cafeeiro em função do suprimento de potássio e cálcio em solução nutritiva. Fitopatologia Brasileira, Brasília, v.28, n.3, p.286-291, 2003

13. Guimarães, P.T.G.; Garcia, A.W.R.; Venegas, V.H.A.; Prezotti, L.C.; Viana, A.S.; Miguel, A.S.; Malavolta, E.; Corrêa, J.B.; Lopes, A.S.; Nogueira, F.D.; Monteiro, A.V.C.; Oliveira, J.A. Cafeeiro. In: Ribeiro, A.C.; Guimarães, P.T.G.; Venega, V.H.A. (Ed.). Recomendações para uso de corretivos e fertilizantes em Minas Gerais: $5^{\text {a }}$ aproximação. Viçosa: Universidade Federal de Viçosa, 1999. p.289-302.

14. Huber, D.M. The role of mineral in defense. In: Horsfall, J.G.; Cowling, E.B. (Eds.). Plant pathology: an advance treatise. New York: Academic Press, 1980. p.341-406.

15. Jones, J.B.; Wolf, B.; Millis, H.A. Plant analysis handbook. Athens: Micro-macro publishing, INC. 1991. 213p

16. Kiehl, J.E. Fertilizantes orgânicos. São Paulo: Agronômica Ceres, 1985. 492p.

17. Malavolta, E.; Vitti, G.C.; Oliveira, S.A. Avaliação do estado nutricional das plantas: princípios e aplicações. 2.ed. Piracicaba: Associação Brasileira para Pesquisa do Fosfato, 1997. 238p.

18. Malavolta, E.; Cruz, V.F. A meaning for foliar diagnosis. In: Samish, R.M. (Ed.). Recent advances in plant nutrition. New York: Gordon \& Breach Science, 1971. 238p.

19. Marschner, H. Mineral nutrition of higher plants. 2.ed. London: Academic Press, 1995. 889p.

20. Martinez, H.E.P.; Menezes, J.F.S.; Souza, R.B.; Venegas, V.H.A ; Guimarães, P.T.G. Faixas críticas de concentrações de nutrientes e avaliação do estado nutricional de cafeeiros em quatro regiões de Minas Gerais. Pesquisa Agropecuária Brasileira, Brasília, DF, v.38, n.6, p.703-713, 2003.

21. Martins, M.; Mendes, A.N.G.; Alvarenga, M.I.N. Incidência de pragas e doenças em agroecossistemas de café orgânico de agricultores familiares em Poço Fundo, MG. Ciência e Agrotecnologia, Lavras, v.28, n.6, p.1306-1313, 2004.

22. Oliveira, C.A.; Pozza, E.A.; Oliveira, V.B.; Santos, E.C.; Chaves, Z.M. Escala diagramática para avaliação da severidade de cercosporiose em folhas de cafeeiro. In: Simpósio dos Cafés do Brasil, 2; 2001, Vitória. Resumos. Vitória: Embrapa, 2001. p.80.

23. Phiri, N.A.; Hillocks, R.J.; Jeffries, P. Incidence and severity of coffee diseases in smallholder plantations in northern Malawi. Crop protection, Oxford, v.20, n.4, p.352-332, 2001.

24. Pozza, A.A.A.; Martinez, H.E.P.; Caixeta, S.L.; Cardoso, A.A.; Zambolim, L.; Pozza, E.A. Influência da nutrição mineral na mancha de olho pardo em mudas de cafeeiro. Pesquisa Agropecuária Brasileira, Brasília, v.36, n.1, p.53-60, 2001.

25. Ricci, M.S.F.; Araújo, M.C.F.; Franch, C.M.C. Cultivo orgânico do café: recomendações técnicas. Brasília: Embrapa, 2002. 101p.

26. Samayoa, J.O.J.; Sanchez, V.G. Enfermedades foliares en café orgânico y convencional. Turrialba, San Jose, n.58, p.9-19, 2000.

27. Shaner, G.; Finney, R.E. The effect of nitrogen fertilization on the expression of slow-mildewing resistance in Knox wheat. Phytopathology, St. Paul, v.70, n.8, p.1183-1186, 1977.

28. Teixeira, H.; Maffia, L. A.; Mizubuti, E.S. Progresso de doenças em sistema convencional e orgânicos de produção de café. Fitopatologia Brasileira, Brasília, v.30, Suplemento, p.146, 2005

29. Vanderplank, J.E. Host-pathogen interactions in plant disease. New York: Academic Press, 1982. 207p.

30. Zambolim, L.; Ventura, J.A. Resistência a doenças induzida pela nutrição mineral das plantas. Revisão Anual de Patologia de Plantas, Passo Fundo, v.1, p.275-318, 1993. 